\title{
A Longitudinal Study of the Reciprocal Effects of Alcohol use and Interpersonal Violence among Australian Young People
}

\author{
Kirsty E. Scholes-Balog ${ }^{1}$, Sheryl A. Hemphill ${ }^{1}$, Peter Kremer $^{2}$ \& John W. Toumbourou ${ }^{3}$
}

${ }^{1}$ School of Psychology, Australian Catholic University, Victoria, Australia, 3065

${ }^{2}$ McCaughey Centre, School of Population Health, Melbourne University, Victoria, Australia, 3053

${ }^{3}$ School of Psychology and Centre for Mental Health and Wellbeing Research, Deakin University, Victoria, Australia, and Centre for Adolescent

Health, Murdoch Childrens Research Institute, Victoria, Australia, 3052

Correspondence concerning this article should be addressed to Dr Kirsty Scholes-Balog, School of Psychology, Australian Catholic University, 115 Victoria Parade, Fitzroy, Victoria 3065, Australia. Email kirsty.balog@acu.edu.au. Ph. 6139953 3117. Fax. 61394172734

\section{Kirsty E. Scholes-Balog, PhD}

School of Psychology, Australian Catholic University, Victoria, Australia, 3065. Research interests: adolescence, substance use, mental health, problem behaviours 
Bio: Dr Kirsty Scholes-Balog is a Postdoctoral Research Fellow in the School of Psychology Senior Proven Researcher Team at Australian Catholic University. She received her doctorate in medicine in 2010 from the University of Western Australia. Her current research interests include substance use, mental health and problem behaviours (particularly problem online behaviours) among adolescents and young adults.

\section{Sheryl A. Hemphill, PhD}

School of Psychology, Australian Catholic University, Victoria, Australia, 3065. Research interests: child, adolescent and young adult social and emotional development; antisocial behaviour; school discipline and behaviour management

Bio: Professor Sheryl Hemphill is a Professor in Psychology at the Australian Catholic University. She received her doctorate in psychology from La Trobe University. Her research interests focus on development across the life span with a particular focus on adolescence, as well as effective programs for preventing and reducing violent, antisocial, and related behaviors.

\section{Peter Kremer, PhD}

McCaughey Centre, School of Population Health, Melbourne University, Victoria, Australia, 3053. Research interests: child and adolescent health and wellbeing; mental health; obesity; physical activity; sport and exercise psychology

Bio: Dr Peter Kremer is a Senior Research Fellow with the McCaughey Centre at the University of Melbourne. He received his doctorate in psychology from the University of Melbourne. His major research interests include the relationship between sport, exercise and physical activity and health outcomes, particularly mental health.

\section{John W. Toumbourou, PhD}


School of Psychology and Centre for Mental Health and Wellbeing Research, Deakin University, Victoria, Australia, and Centre for Adolescent Health, Murdoch Childrens Research Institute, Victoria, Australia, 3052. Research Interests: drug abuse prevention; adolescent health promotion and the role of the family, peers and community; healthy youth development

Bio: Professor Toumbourou is the Associate Dean (Partnerships and Workplace), in the Faculty of Health and the Professor and Chair in Health Psychology within the School of Psychology at Deakin University. He received his doctorate in psychology from the University of Melbourne. His research interests include drug abuse prevention; adolescent health promotion and the role of the family, peers and community, and healthy youth development.

Acknowledgements: Grant support was provided by the National Institute on Drug Abuse (R01-DA012140-05), the National Institute on Alcoholism and Alcohol Abuse (R01AA017188-01), the Australian National Health and Medical Research Council (project number 594793) and the Australian Research Council Discovery Projects (DPO663371, DPO877359 and DP1095744). The content is solely the responsibility of the authors and does not necessarily represent the official views of the sponsors. The authors also wish to express their appreciation to project staff and participants for their valuable contribution to the project.

K.S-B conceived the design of this paper, completed the statistical analyses and drafted the manuscript. S.H contributed to the design of the original study and the design of this paper, provided advice on statistical analyses and contributed to critical redrafting of the manuscript. P.K 
contributed to the design of the design of this paper, provided advice on statistical analyses and contributed to critical redrafting of the manuscript. J.T. contributed to the design of the original study and the design of this paper, provided advice on statistical analyses and contributed to critical redrafting of the manuscript. All authors read and approved the final manuscript.

\begin{abstract}
The impact of alcohol-related violence on individuals and society continues to receive attention from both media and policy makers. However, the longitudinal relationship between alcohol consumption and violence is unclear, with findings from prospective studies producing mixed results. The current study utilized Australian data from the International Youth Development Study (IYDS) to examine longitudinal relationships between alcohol consumption and severe interpersonal violence across the developmental periods of early adolescence to late adolescence/emerging adulthood. The full sample comprised 849 adolescents (53.8\% female) who had been followed up over a 5 year period, from Grade 7 secondary school (age 13) until Grade 11 secondary school (age 17). Cross-lagged path analysis was used to examine reciprocal relationships between alcohol consumption and interpersonal violence; analyses controlled for a range of covariates considered to be common risk factors for both behaviors. Alcohol use during early and mid adolescence was found to predict violence two years later, whereas a bidirectional relationship between adolescent heavy episodic drinking and violence was observed. Some of these relationships were not significant when covariates such as family conflict and affiliation with antisocial and drug using friends were included in the models. These findings
\end{abstract}


suggest that risk processes begin in late childhood or very early adolescence; efforts to reduce one problem behavior are likely to reduce the other. Further, the role that social and family contexts have in influencing the relationships between alcohol use and interpersonal violence should be considered in future research to better inform preventive efforts.

Keywords: alcohol; heavy episodic drinking; violence; longitudinal; path analysis; adolescence

\section{Introduction}

In Australia and in other developed countries, the impact of alcohol consumption is of growing concern, and the high economic cost and harms associated with alcohol-related violence receive continuing attention from both media and policy makers (Toumbourou et al. 2007). The most recent National Drug Strategy Household Survey in Australia found that approximately 1 in 5 Australians aged 14 years or older drink at levels that put them at risk of alcohol-related disease or injury throughout their lifetime (Australian Insititute of Health and Welfare 2011). In the same survey, approximately 2 in 5 Australians aged 14 years or older reported a pattern of drinking which placed them at risk of alcohol-related injury from a single drinking occasion, at least once in the past 12 months (Australian Insititute of Health and Welfare 2011). In Australia, research indicates that alcohol is implicated in a substantial proportion of violent behaviors such as assault. For example, a study of individuals presenting to a hospital emergency department found that among patients presenting with injuries resulting from interpersonal violence, almost two thirds reported drinking alcohol prior to their injury (Poynton et al. 2005). Further, in 2007, data obtained from the Australian Institute of Criminology's Drug Use Monitoring Australia (DUMA) program showed that, across Australia, half of all people detained by police for disorder and violent offences had consumed alcohol in the 48 hours prior to the arrest (Adams et al. 2008). Re-analysis of this data revealed that, among 
those charged specifically for assault, $52 \%$ had consumed alcohol in the previous 24 hours, and $36 \%$ reported that the consumption of alcohol directly contributed to the offense (Morgan and McAtamney 2009). Clearly, the relationship between alcohol use and violent behavior requires attention.

There are five competing theoretical models that have been hypothesized to explain the association between alcohol use and violence (for a review of these models see Wagner 1996). In the first model, alcohol use has been suggested to cause violent behavior either due to the direct pharmacological effects of intoxication and/or the situational factors associated with intoxication, or by motivating offending to generate income to support heavy alcohol/substance use. On the other hand, in the second model violent behavior is suggested to lead to alcohol use as a consequence of involvement in a violent lifestyle. Within this model, heavy use of alcohol is suggested to represent an unconventional and criminal image and may fit within a deviant identity and vision of the world. Further, aggressive individuals are thought to be more likely to select or be pushed into social situations that encourage competitive heavy drinking. The third model is a combination of the previous two; this model argues that alcohol use and violence have a reciprocal relationship whereby alcohol use increases violent behavior and violent behavior increases alcohol use. The fourth model hypothesizes that the relationship between alcohol use and violent behavior is not causal; rather, this association is thought to arise due to common psychological or social causes of both behaviors. Finally, the fifth model suggests that a relationship between alcohol use and violence is simply coincident. This model proposes that alcohol use and violent behavior are distinct phenomena with independent causes, and their association reflects the synchronous occurrence of both behaviors during the same period of development. 
Each of the above models proposes a different temporal relationship between alcohol use and violence and not all can be tested or evaluated using the same methodology, given the different time lags suggested by each model (for example, the direct pharmacological effects model suggests that alcohol use has a direct effect on subsequent violent behavior that occurs in close temporal sequence to the alcohol consumption, whereas alcohol may also precede violence that occurs at much later time points, and is motivated as a means of generating income to support continued heavy alcohol use). The current study attempts to examine the directionality of the relationship between alcohol use and violence (i.e., whether alcohol use precedes violence, or violence precedes alcohol use, or whether the two behaviors exhibit reciprocal relationships) and whether these relationships can be explained by common risk factors.

A number of longitudinal studies have attempted to evaluate the relationship between alcohol use and violence; however, the findings from these studies have been mixed. Some studies have found that early alcohol use predicts later violent behavior (Ellickson et al. 2003; Dembo et al. 1993; Newcomb and McGee 1989; Temple et al. 2012; Fergusson and Horwood 2000; Swahn and Donovan 2004; Boden et al. 2012; Green et al. 2011). Others have found that early violent behavior predicts subsequent increases in alcohol use (White and Hansell 1996; White et al. 1993). White and Hansell (1996) also reported a relationship between early alcohol use and later violent behavior; however, this was in the opposite direction to that predicted, with higher levels of alcohol use predicting decreases in later aggression. Other studies have found bidirectional relationships between alcohol use and aggression, with early alcohol use associated with increased later aggression as well as early aggression associated with increased later alcohol use (Xue et al. 2009; White et al. 1999; Windle 1990; Huang et al. 2001; Wei et al. 2004; White et al. 2012; Parks et al. 2008). Further, some studies suggest that the relationship between alcohol use and violence reflects common 
underlying risk factors, as these associations appear attenuated or no longer statistically significant when controlling for common causes (e.g., Huang et al. 2001; Boden et al. 2012). Other studies have found that the strength of the relationships are not reduced substantially when controlling for common risk factors, suggesting that the relationship between alcohol use and violence is not spurious (White et al. 1999).

There are a number of limitations of the existing literature examining the longitudinal relationships between alcohol use and violence. These limitations may have contributed to the inconsistency in the published literature. First, few studies examine these relationships across a broad developmental time period. It is possible that these relationships differ as a function of developmental stage. Examining the relationships between alcohol use and violence across early, mid and late adolescence/emerging adulthood would allow investigation of this issue. Differences as a function of age might be predicted in light of Moffitt's view of adolescence-limited antisocial behavior (Moffitt 1993). According to Moffitt, within the phenomenon of juvenile delinquency there are two groups; the largest group consists of those adolescents who exhibit antisocial behavior only in adolescence, termed "adolescence-limited" antisocial behavior, while a much smaller group continues to exhibit serious antisocial behavior throughout adulthood, termed "life course-persistent" antisocial behavior (Moffitt 1993). Thus, adolescence-limited antisocial behavior may exhibit age specific relationships with violent behavior as compared to life-course persistent antisocial behavior (Xue et al. 2009). Second, many of the samples used in these longitudinal studies are restricted and possibly biased. For example, some studies use juvenile justice samples (e.g., Dembo et al. 1993), and others include only males (e.g., White et al. 1999; White et al. 2012). Further, there is inconsistency in the measurement and classification of alcohol use across the studies. Many studies only examine frequency of alcohol use (White et al. 1999; Newcomb and McGee 1989) or a dichotomous measure of alcohol use versus no use (Ellickson et al. 2003), rather than 
examining phenomena such as binge drinking/heavy episodic drinking (HED). Inconsistency in the literature may partially reflect differences in the measurement of alcohol use, and different relationships between violence and alcohol use as a function of the aspect of alcohol use captured by the measure used. Similarly, inconsistency may result from the examination of different types of violent behaviors, with different violent behaviors showing different relationships with alcohol consumption (e.g., Parks et al. 2008). Finally, the extant literature examining longitudinal relationships between alcohol use and violence is primarily from the United States (US). Given the policy differences between the US and Australia, it is of interest to examine whether similar relationships between alcohol use and violence are observed among Australian young people. Future research addressing these limitations would greatly advance this field of study.

Another important issue in the extant literature concerns control for factors that could potentially confound, or account for, relationships between alcohol use and violence. While most studies include some covariates in their analyses, typically only a few covariates are considered, such as academic achievement (Huang et al. 2001; Xue et al. 2009; White et al. 1999), depression (Huang et al. 2001; Xue et al. 2009; White et al. 1999) and family conflict (Xue et al. 2009). More importantly, the vast majority of studies fail to include time varying covariates, which may result in insufficient adjustment for potential confounding. Failure to control for potentially important confounds limits the confidence in the attribution of relationships between alcohol use and violence to direct effects of one factor on another, as opposed to indirect or meditational relationships. This distinction is important in understanding the mechanisms through which alcohol use and violence may be related, and thus the implications of these relationships for prevention efforts. There are many risk factors that are common to both alcohol use and violence. In addition to those described above (depression, family conflict and acadmic failure), affiliation with deviant peers and friends who use drugs are 
both strong risk factors for alcohol use (Hawkins et al. 1992) and violent behaviors (Hawkins et al. 1998). Similarly, low socioeconomic status has shown to be predictive of both violence (Foshee et al. 2008; Sussman et al. 2004) and alcohol consumption (Huckle et al. 2010).

Consideration of such common risk factors when assessing relationships between alcohol use and violence is important to understand more thoroughly the basis of any relationships between alcohol use and violence

\section{Aims and hypotheses}

In light of the identified limitations and constraints evident in the extant literature, the aim of the current study was to examine longitudinal relationships between alcohol use (both the frequency of alcohol use and the frequency of HED) and severe interpersonal violent behavior in Australian youth, across the developmental periods of early adolescence to late adolescence/emerging adulthood. The analyses will address many of the limitations of the available literature and will control for a number of time-varying covariates that are suggested to be risk factors for both alcohol use and violence, including interaction with antisocial friends, friends' drug use, family conflict, depressive symptoms and academic failure. This will allow determination of whether relationships between alcohol use and violent behavior can be explained by these common risk factors. Further, given that studies have observed differences in the developmental trajectory of both alcohol use and violence as a function of gender (Xue et al. 2009), and gender differences in the relationship between alcohol use and violence (Young et al. 2008), multiplegroup analyses will be conducted to test for gender differences in the cross-lagged relationships between alcohol use and violence. Given the inconsistent findings in the published literature, no predictions were made as to the directional relationship between alcohol use and violence, or which associated theoretical model would best represent the data. 


\section{Method}

\section{Participants}

Participants for this study were youth from Victoria, Australia, who were involved in the International Youth Development Study (IYDS). The IYDS is a two-nation longitudinal study investigating the development of healthy and problem behaviors among young people in Victoria, Australia, and Washington State, United States. The IYDS contains three cohorts, all of which were originally recruited in 2002: youngest cohort (recruited when in Grade 5; age 11), middle cohort (recruited when in Grade 7; age 13) and oldest cohort (recruited when in Grade 9; age 15). The youngest Victorian cohort forms the sample for the current analyses; this cohort comprised 927 students and was chosen as it has been followed up most extensively since their original recruitment in 2002; participants have been followed up every 1-2 years until the age of 19 .

The original recruitment and sampling for the IYDS has been described in detail elsewhere (McMorris et al. 2007). Briefly, the IYDS used a two-stage cluster sampling approach. Stage one of sampling involved random selection of public and private schools stratified according to geographic location, using a probability proportionate to grade-level size sample procedure. In the second stage of sampling, one class at each target year level (Grades 5, 7 and 9), within each school, was selected at random.

For the purpose of the current analyses, three measurement points were selected to examine reciprocal longitudinal relationships between alcohol use and violent behavior; these measurement points were Grade 7 (age 13), Grade 9 (age 15) and Grade 11 (age 17). These measurement 
points were chosen as they span early-mid-late adolescence, at two year intervals, and at these time points all variables of interest were measured, enabling longitudinal analysis.

\section{Measures}

Alcohol use. Alcohol consumption was assessed at each measurement point with two items. To measure past year alcohol use, participants were asked "In the past year (12 months), on how many occasions have you had an alcoholic beverages (like beer, wine or liquor/spirits) to drinkmore than just a few sips?". This item was rated on an 8-point scale from "Never" (1) to "40+ times" (8). To measure heavy episodic drinking (HED), participants were asked "Think back over the last 2 weeks. How many times have you had 5 or more drinks in a row?". This item was rated on a 6-point scale from "None" (1) to "10 or more times" (6). Although these are ordinal variables, both were scored on scales with more than 5 categories, and are assumed to represent an underlying continuum of frequency of alcohol use/HED, hence they were treated as continuous for the purpose of path analysis (Johnson and Creech 1983; Hutchinson and Olmos 1998).

Severe interpersonal violence. Interpersonal violence was assessed at each measurement point with two items. The first item asked "How many times in the past year (12 months) have you beaten up someone so badly that they probably needed to see a doctor or nurse?", and the second item asked "How many times in the past year (12 months) have you attacked someone with the idea of seriously hurting them?". Each of these items was rated on an 8-point scale from "Never" (1) to "40+ times"(8). A composite score for severe interpersonal violence was constructed from these two items by taking the average of the two items (where respondents had answered both violence questions). 
Time varying covariates. A number of risk factors identified in the literature as being common to both alcohol use and violent behavior (Hawkins et al. 1992; Hawkins et al. 1998) were considered as covariates for the analyses. Four of the covariates (academic failure, friends' use of drugs, interaction with antisocial friends and family conflict) were drawn from a modified version of the Communities That Care youth survey (Glaser et al. 2005). Scale scores for these four covariates were obtained by taking the mean score across the items (where respondents had answered all items in the scale); higher scale scores reflect poorer adjustment (Glaser et al. 2005).

Academic failure. The scale measure academic failure contained 2 items, each of which was measured on a 4-point scale (1-4). Example item: "Putting them all together, what were your grades/marks like last year?"

Friends' use of drugs. The scale measuring friends' use of drugs contained 4 items, each of which was measured on a 5-point scale (0-4).

Example item: "In the past year (12 months), how many of your best friends' have used marijuana (pot, weed, grass)?"

Interaction with antisocial friends. The scale measuring interaction with antisocial friends contained 8 items, each of which was measured on a 5-point scale (0-4). Example item: “In the past year (12 months), how many of your best friends have stolen something worth more than $\$ 5 / 10$ ?" Family conflict. The scale measuring family conflict comprised 3 items, each of which was measured on a 4-point scale (1-4). Example item: "People in my family have serious arguments".

Depressive symptoms. Depressive symptoms, as measured using the Short Mood and Feelings Questionnaire (SMFQ) (Angold et al. 1995), was also considered as a covariate. This scale has established reliability and validity and was designed for use in epidemiological survey research 
involving adolescents (Angold et al. 1995). The scale consists of 13 items with a common response format: never (0), sometimes (1) and always (2). Scores range from 0 to 26, with high levels of depressive symptoms represented by scores greater than 12 (Angold et al. 1995).

\section{Time invariant covariates.}

Primary parental education level. Primary parental education level (as reported by the student's primary parent in a separate interview with parents) was used as a proxy measure of household socio-economic status. It was assessed with an item asking "What is the highest level of education you have achieved". Response options ranged from "less than year 7" to "postgraduate university". The responses to this item were dichotomized to reflect completion of secondary school versus incomplete secondary school. Primary parental education level is a time invariant covariate as it was measured when the participants were first recruited into the IYDS. $64.4 \%$ of the sample had a primary parent who had completed at least secondary school.

Early antisocial behavior. Early antisocial behavior (measured in grade 5 primary school; age 11) was included as a time invariant covariate.

This antisocial behavior scale was drawn from a modified version of the Communities That Care youth survey (Glaser et al. 2005). It contained 5 items, each measured on a 4-point scale (1-4) (For example, “Have you ever been suspended from school?”).

\section{Procedure}

Ethics approval for the IYDS was obtained from the Royal Children's Hospital Ethics in Human Research Committee and from The University of Melbourne Human Ethics in Research Committee. This study was performed in accordance with the ethical standards laid down in the 1964 Declaration of Helsinki. Permission to conduct research in schools was obtained from relevant authorities for public and private 
schools, and from school principals. Surveys took approximately 50-60 minutes to complete. Surveys completed during secondary school were group-administered in the students' classrooms; parents gave written informed consent and students also gave their assent for participation.

Students no longer attending school during the follow-up surveys, or who were absent on the day of the survey, were surveyed individually by trained personnel. After each survey, participants received a small thank you gift.

\section{Statistical analyses}

Analysis for this study consisted of a number of steps. First, missing values analysis was completed using PASW Statistics 18 (SPSS). Cases with more than $60 \%$ missing values on variables of interest to the current study were deleted. This resulted in the deletion of 78 cases $(8.41 \%)$. Expectation maximization (EM) was then used to impute the remaining missing values in the data set. EM has been shown to produce correct parameter estimates but may produce biased standard errors and significance values (Schafer and Graham 2002; von Hippel 2004).

Utilizing this imputed data set, cross-lagged path analysis using AMOS 17 was then conducted to test for reciprocal associations between violent behavior and 1) past year alcohol use, and 2) HED. In these analyses, violent behavior and alcohol consumption measures were modeled as both predictors and outcomes across adjacent time points, taking into account autoregressive effects. Initial analyses were conducted on the imputed data set in order to check the fit of the model and normality statistics as well as to obtain modification indices (where necessary) and the BollenSteine bootstrap p-value (for models with multivariate non-normality). Following this, all analyses were repeated on the full, non-imputed data set using full information maximum likelihood (FIML) estimation to obtain correct parameter estimates and path significance, and to confirm the findings observed in the bootstrapped analyses. Fit statistics, path coefficients, and statistical significance values obtained from FIML analyses 
are reported. Multi-group analyses (gender variant and gender invariant models), with nested model comparisons, were conducted to examine gender differences in the models. Further, critical ratio differences of path coefficients were examined to check for statistically significant differences in the path coefficients as a function of gender.

To investigate the role of the covariates in these models, first, a series of correlations was produced to examine associations between alcohol use, violent behavior and each of the covariates. All covariates demonstrated statistically significant correlations with the measures of alcohol consumption and interpersonal violence at each measurement point, therefore, the cross-lagged models were then replicated with the inclusion of each covariate. Each covariate was added separately, and then the model tested, in order to examine the unique contribution of each covariate to the statistical significance of the cross-lagged pathways.

The degree of model fit was assessed using the chi-square goodness of fit statistic, the Root Mean Square Error of Approximation (RMSEA), the Comparative Fit Index (CFI) and the Tucker Lewis Index (TLI). The model was considered to be a good fit if RMSEA was less than 0.06, and both CFI and TLI were close to or greater than 0.95 (Hu and Bentler 1999).

\section{Results}

Summary statistics and reliability for each variable across each measurement point, for males and females separately, are reported in Table 1. Rates of past year alcohol use, HED and severe interpersonal violence are reported in Table 2. These rates were calculated as the number of participants who reported at least one occasion of past year alcohol use, HED, or interpersonal violence (respectively), at the specified 
measurement point. As can be seen, rates of past year alcohol use and HED increased dramatically over the measurement points, for both males and females. On the other hand, rates of severe interpersonal violence increased slightly among males across the measurement points, but remained relatively low and stable among females.

Cross-sectional correlations between severe interpersonal violence, past year alcohol use and HED, at each measurement wave, for males and females separately, are presented in Table 3. Statistically significant moderate to strong correlations were observed between past year alcohol use and HED, for both males and females. Similarly, statistically significant, but weaker, correlations were observed between interpersonal violence and each measure of alcohol use, for males and females.

Cross lagged relationship between past year alcohol use and violence. The initial model of the reciprocal relationship between past year alcohol use and severe interpersonal violence is summarized in Figure 1. Mardia's coefficient indicated a violation of multivariate kurtosis for this model, therefore the Bollen-Steine bootstrap corrected p-value was used to evaluate the fit of the models. The gender group-invariant model fit the data well $\chi^{2}(16)=46.14, p<0.001$ (Bollen-Steine bootstrap $p$ from imputed data $\left.=0.280\right) ;$ RMSEA =0.05; TLI = 0.86; CFI = 0.95), as did the gender group-variant model $\left(\chi^{2}(18)=21.52, p=0.006\right.$ (Bollen-Steine bootstrap $p$ from imputed data $\left.=0.221\right) ;$ RMSEA $=0.04$; $T L I=0.87 ; C F I=0.98$ ). Nested model comparisons showed a statistically significant difference between the group invariant and the group variant models $\left(\chi^{2}(8)=24.62, p=0.002\right)$, indicating that the gender variant model was the more parsimonious model. In this model, past year alcohol use demonstrated moderate to high temporal stability for both males and females; however, temporal stability in severe interpersonal violence was evident only for males. Past year alcohol use in Grade 7 was found to predict Grade 9 interpersonal violence for both males and 
females (M: $\beta=0.12, p=0.013, \mathrm{~F}: \beta=0.21, p<0.001)$. Similarly, past year alcohol use in Grade 9 was found to predict Grade 11 interpersonal violence. This path was statistically significant for males only (M: $\beta=0.12, p=0.039, \mathrm{~F}: \beta=0.04, p=0.421$ ); however, the critical ratio difference test for the path coefficient was not statistically significant $(p>0.05)$, indicating no difference in this path coefficient between males and females. All pathways from interpersonal violence to later alcohol use did not reach statistical significance for both males and females.

Each covariate was then added to this model; the level of each covariate at the preceding survey was controlled for at the subsequent survey. With the addition of each covariate, the path from Grade 7 alcohol use to Grade 9 interpersonal violence remained statistically significant for both males and females (depressive symptoms [M: $\beta=0.12, p=0.013 \mathrm{~F}: \beta=0.18 ; p<0.001]$, academic failure [M: $\beta=0.13, p=$ $0.010 ; \mathrm{F}: \beta=0.22 ; p<0.001]$, friends' use of drugs $[\mathrm{M}: \beta=0.10, p=0.049 ; \mathrm{F}: \beta=0.19 ; p<0.001]$, interaction with antisocial friends $[\mathrm{M}: \beta=$ $0.12, p=0.026 ; \mathrm{F}: \beta=0.18 ; p<0.001]$; family conflict $[\mathrm{M}: \beta=0.13, p=0.009 ; \mathrm{F}: \beta=0.17 ; p<0.001]$, early antisocial behavior $[\mathrm{M}: \beta=0.12, p$ $=0.018 ; \mathrm{F}: \beta=0.20 ; p<0.001]$ and parental education $[\mathrm{M}: \beta=0.12, p=0.012 ; \mathrm{F}: \beta=0.21 ; p<0.001]$ ). The path from Grade 9 alcohol use to Grade 11 interpersonal violence retained statistical significance among males with the inclusion of the covariates depressive symptoms [M: $\beta=$ $0.12, p=0.032]$, early antisocial behavior $[\mathrm{M}: \beta=0.12, p=0.035]$ and family conflict $[\mathrm{M}: \beta=0.12, p=0.044]$; however, with the addition of the covariates interaction with antisocial friends [M: $\beta=0.05, p=0.385]$, friends' use of drugs $[\mathrm{M}: \beta=0.18, p=0.192]$, parental education [M: $\beta=0.10, p=0.073]$ and academic failure $[\mathrm{M}: \beta=0.11, p=0.061]$, this path was no longer statistically significant.

Cross lagged relationship between heavy episodic drinking and violence. The initial model of the reciprocal relationship between HED and severe interpersonal violence is summarized in Figure 2. Mardia's coefficient indicated a violation of multivariate kurtosis for this 
model, therefore the Bollen-Steine bootstrap corrected p-value was used to evaluate the fit of the models. The gender group-invariant model fit the data well $\left(\chi^{2}(16)=46.75, p<0.001\right.$ (Bollen-Steine bootstrap $p$ from imputed data $\left.=0.264\right) ; R M S E A=0.05 ; T L I=0.75 ; C F I=0.91$ ), as did the gender group-variant model $\left(\chi^{2}(8)=27.69, p=0.001\right.$ (Bollen-Steine bootstrap $p$ from imputed data=0.138); RMSEA =0.05; TLI=0.68; CFI $=0.94)$. Nested model comparisons showed a statistically significant difference between the group invariant and the group variant models $\left(\chi^{2}(8)\right.$ $=19.06, p=0.015$, indicating that the gender variant model was the more parsimonious model. In this model HED demonstrated moderate statistically significant temporal stability for both males and females. Statistically significant temporal stability in severe interpersonal violence was evident only for males. HED in Grade 7 was found to predict Grade 9 interpersonal violence for females only (M: $\beta=0.06, p=0.199$, F: $\beta=$ $0.10, p=0.024)$; however, the critical ratio difference test for the path coefficient was not statistically significant $(p>0.05)$. Conversely, Grade 9 interpersonal violence was found to predict Grade $11 \mathrm{HED}$ for females only ( $\mathrm{M}: \beta=0.06, p=0.129, \mathrm{~F}: \beta=0.15, p=0.002$ ); the critical ratio difference test for this path coefficient was statistically significant $(p<0.05)$ indicating a difference in this path coefficient between males and females.

Each covariate was then added to this model; the level of each covariate at the preceding survey was controlled for at the subsequent survey. The path from Grade 7 HED to Grade 9 interpersonal violence remained statistically significant for females with the addition of the covariates depressive symptoms [F: $\beta=0.09 ; p=0.039$ ], academic failure [F: $\beta=0.10 ; p=0.022]$, early antisocial behavior [F: $\beta=0.09 ; p=$ 0.047] and parental education [F: $\beta=0.11 ; p=0.018]$, but was not statistically significant with the covariates friends' use of drugs [F: $\beta=0.06$; $p=0.209]$, family conflict $[\mathrm{F}: \beta=0.07 ; p=0.104]$ and interaction with antisocial friends [F: $\beta=0.06 ; p=0.202]$. The path from Grade 9 
interpersonal violence to Grade 11 HED retained statistical significance among females with the inclusion of all covariates (depressive symptoms [F: $\beta=0.14, p=0.003$ ], academic failure [F: $\beta=0.14, p=0.003]$, friends' use of drugs [F: $\beta=0.13, p=0.006]$, interaction with antisocial friends' [F: $\beta=0.18, p<0.001]$; family conflict [F: $\beta=0.16, p<0.001]$, early antisocial behavior [F: $\beta=0.14, p=0.003]$ and parental education $[\mathrm{F}: \beta=0.15, p=0.001])$.

\section{Discussion}

The impact of alcohol-related violence on individuals and society continues to generate interest and concern from both media and policy makers. However, the longitudinal relationship between alcohol consumption and violence is unclear, with findings from prospective studies producing mixed results. Inconsistency in the published literature could be owing to a number of factors, including: differences as a function of age/developmental stage, gender differences, differences in measurement and conceptualization of both alcohol consumption and violent behavior, and control (or failure to) of potentially important confounds or common risk factors. The current study utilized Australian data from the International Youth Development Study (IYDS) to examine longitudinal relationships between alcohol consumption and severe interpersonal violence across the developmental periods of early adolescence to late adolescence/emerging young adulthood. Cross-lagged path analysis was used to examine reciprocal relationships between alcohol consumption and interpersonal violence. Analyses controlled for a range of covariates considered to be common risk factors for both behaviors; alcohol use was measured in terms of both frequency of alcohol consumption as well as frequency of heavy episodic drinking (HED), and models tested for gender differences in the relationships between alcohol use and interpersonal violence. Thus, the current study was able to address many of the limitations evident in the published literature. 
In the current study, different relationships between alcohol use and severe interpersonal violence were observed when utilizing different measures of alcohol consumption. When examining the frequency of alcohol use, the predominant relationship was from alcohol use to violence. Grade 7 frequency of alcohol use was found to predict Grade 9 interpersonal violence, and Grade 9 frequency of alcohol use was found to predict Grade 11 interpersonal violence. On the other hand, a bi-directional relationship between the frequency of HED and severe interpersonal violence was observed. Grade 7 HED was found to predict Grade 9 interpersonal violence; whereas Grade 9 interpersonal violence was found to predict Grade 11 HED (the latter path was found only among females). The addition of covariates measuring family conflict and peer antisocial behavior and drug use reduced some of these relationships to statistical non-significance. These findings have implications for understanding the mechanisms underlying associations between alcohol consumption and violent behaviors.

Consistent with a number of studies (e.g., Ellickson et al. 2003; Dembo et al. 1993; Newcomb and McGee 1989; Temple et al. 2012; Fergusson and Horwood 2000; Swahn and Donovan 2004; Boden et al. 2012; Green et al. 2011), the frequency of early and mid adolescent alcohol use was found to predict violent behavior later in adolescence. The relationship between Grade 7 alcohol use and Grade 9 severe interpersonal violence remained statistically significant even with the addition of a range of time-varying covariates considered to be common risk factors for both alcohol use and violence. These covariates included peer drug use and antisocial behavior, family conflict, depressive symptoms and academic failure. This finding provides support for the theoretical model that proposes that early alcohol use has a direct effect on later violent behavior. The direct effect of alcohol consumption on later violence has been suggested to be due to the direct pharmacological effects of intoxication and/or the situational factors associated with intoxication, or to generate income to support heavy alcohol/substance use 
(Wagner 1996). Given the 2 year time lag between measurements in the current study, it is unlikely this direct relationship reflects acute pharmacological or situational effects associated with intoxication; rather, as noted above, this observed relationship may be more likely to reflect a motivation to engage in violence to generate income to maintain the consumption of alcohol. It should be noted that even though this path remained statistically significant with the addition of these covariates, the $p$ value was 0.049 with the addition of the friends' use of drugs covariate. Additionally, it is possible that the relationship between adolescent alcohol use and later violence arises due to other unmeasured common psychological or social influences.

Our finding is in contrast to studies that have found no relationship between the frequency of adolescent alcohol and later violent behavior (e.g., White et al. 1993) and one study that even found a negative relationship between early alcohol use and later violent behavior (White and Hansell 1996). The former study included a small sample of males only (White et al. 1993), while the latter study confounded age by combining participants varying in age by 6 years at each time point (White and Hansell 1996). Therefore, any age specific impact of alcohol use (as evident in the current study) on later violent behavior may have been diluted. Further, both of these studies utilized data collected in the 1970s and 1980s, which may not accurately reflect current levels of alcohol use and violent behaviors, and thus, the contemporaneous relationship between these two behaviors.

On the other hand, the relationship between Grade 9 alcohol use and Grade 11 interpersonal violence no longer remained with the addition of the peer antisocial behavior and drug covariates, as well as the academic failure and parental education level covariates. These findings suggest that during mid to late adolescence, the relationship between alcohol use and violence is more complex than a direct 
relationship, and arises due to common social and contextual factors that influence both alcohol use and violence. The role of peers in influencing behaviors such as alcohol use has been shown to increase throughout adolescence (Ferguson and Meehan 2011). Therefore, it is possible that, early in adolescence, the impact of alcohol use on later violent behavior is a robust direct effect, but later, as peers begin to have a stronger influence on behavior, alcohol use may impact on later violent behaviors through social contexts such as affiliation with deviant peers.

The current study not only examined the longitudinal relationship between the frequency of alcohol use and severe interpersonal violence but also the relationship between the frequency of HED and severe interpersonal violence. Interestingly, the findings differed depending on the measure of alcohol consumption. That is, while the frequency of alcohol use was associated with later interpersonal violence, a bi-directional relationship was identified between the frequency of HED and interpersonal violence. Grade 7 HED was found to predict Grade 9 interpersonal violence, whereas, Grade 9 interpersonal violence was found to predict later HED (Grade 11) but only among females. These findings are consistent with a number of studies that have also identified bi-directional relationships between violence and measures of alcohol consumption (Xue et al. 2009; White et al. 1999; Windle 1990; Huang et al. 2001; Wei et al. 2004; White et al. 2012; Parks et al. 2008). The relationship between early HED and later violent behavior no longer remained when the covariates of family conflict and peer antisocial behavior and drug use were added to the model, suggesting that these associations arise due to these common risk factors. Only one previous study finding bidirectional relationships controlled for a range of covariates similar to those considered here (Xue et al. 2009). In that study, the bi-directional relationships remained statistically significant, but were reduced substantially in magnitude, lending support to the suggestion that these bidirectional relationships may be explained, at least in part, by common risk factors. On the other hand, in the current study the relationship 
between mid adolescent interpersonal violence (Grade 9) and late adolescent HED remained statistically significant with the addition of each covariate. This is consistent with the hypothesis that heavy alcohol use arises as a consequence of involvement in a violent lifestyle, as it fits with a deviant identity and vision of the world (Wagner 1996). It is interesting that interpersonal violence was found to be predictive of later HED, but not of later alcohol use. This is consistent with the above model, given that alcohol use itself may not be considered a deviant behavior, whereas HED is more unconventional. Again, it should be noted that, although this path remained statistically significant with the addition of a range of covariates, it is possible that this relationship may be explained by other unmeasured social or psychological common influences.

In the current study, differences in the relationships between alcohol use/HED and violence were observed as a function of developmental stage. Relationships between alcohol use/HED and later interpersonal violence were stronger in early-mid adolescence, whereas as relationship between interpersonal violence and later HED was observed only in mid-late adolescence. Studies that have examined emerging adulthood have observed much stronger associations during early adolescence than late adolescence/young adulthood (e.g., Xue et al. 2009). Purchasing of alcohol during adolescence (under the age of 18 in Australia) is illegal, and thus alcohol use represents some degree of unconventionality (though it becomes much more common as adolescents approach the age of 18, as is evident in the current study). It has been suggested that adolescents who use alcohol/binge drink early in adolescence may adhere less to conventional norms and may be more deviant, whereas alcohol use/HED in emerging adulthood is more conventional, more socially acceptable, and legal above the age of 18 (in Australia), and thus does not fundamentally the reflect rejection of social norms (Xue et al. 2009). Thus, it would follow that stronger associations between 
alcohol use and violence would be observed earlier in adolescence as a reflection of a general problem behavior syndrome (Jessor and Jessor 1977). Alternatively, weaker relationships between alcohol use/HED and violence in late adolescence/young adulthood may fit with Moffitt's view of adolescence-limited antisocial behavior (Moffitt 1993). Although the current study examined the relationships between alcohol use and violence up until late adolescence, we were not able to track these relationships further into young adulthood and thus could not test whether longitudinal relationships between alcohol use and violence continued into young adulthood. Investigation of these relationships further into the transition from late adolescence to young adulthood would be of interest in future research.

There are a number of limitations to the current study that should be noted. First, the current study relied on self-report data, which may be affected by social desirability. However, studies suggest that self-report methods offer a valid and reliable means of assessing both alcohol use (Winters et al. 1990; Barnea et al. 1987) and delinquency (Thornberry and Krohn 2000). Second, the current study included only two items assessing the perpetration of interpersonal violence (these items assessed whether participants had beaten someone up or attacked someone with the intent of harming them), and thus was not able to investigate other violent behaviors such rape and intimate partner violence. The behaviors assessed by this measure were quite narrow and severe, and thus the findings may not be comparable to studies that used broader measures of less severe violent behaviors. Third, the prevalence and frequency of severe interpersonal violence in the current sample was quite low, particularly among females. However, this is reflective of the use of a general population school-based sample, and thus the findings are generalisable to this population group. These limitations should be considered when interpreting the findings of the current study. 
Despite the above limitations, there are several notable strengths to the current study. This study utilized a large longitudinal data set and was able to examine reciprocal relationships (within the one analysis, and taking into account autoregressive effects) between alcohol use and severe interpersonal violence. It was possible to examine whether these relationships differed as a function of developmental stages (early adolescence versus mid-adolescence versus late adolescence/emerging adulthood), and we indeed noted differences as a function of age. Further, two different measures of alcohol consumption were examined: the frequency of alcohol use and the frequency of HED. Again, different relationships were observed with these two different measures of alcohol consumption. Importantly, the current study controlled for a range of time-varying covariates that rarely have been considered in studies of this type. Finally, while the majority of the literature examining longitudinal relationships between alcohol use and violence utilizes samples from the US, the current study utilized a sample of Australian youth, demonstrating that similar relationships between alcohol use and violence exist in countries with differing policy contexts (particularly with respect to alcohol use).

The current findings showing longitudinal associations between alcohol use/HED and severe interpersonal violence have important implications for prevention efforts. Preventive efforts are likely to be most effective if implemented during late childhood or very early adolescence, given that relationships between alcohol use/HED and later violence were observed at the earliest time points in the current study (between the ages of 13 and 15). Further, common risk factors associated with alcohol use/HED and violence should be targeted, particularly with respect to social and family contexts such as affiliation with deviant peers and living in families with high levels of conflict, given that the paths between alcohol consumption and later interpersonal violence were reduced to statistical non-significance when these covariates were 
included in the models. Finally, given that a bi-directional relationship was found between HED and interpersonal violence, efforts to reduce one problem are likely to reduce the other. Therefore, programs and policies that address both youth violence and HED should take into consideration this link, and particularly the contribution that common risk factors, such as affiliation with deviant friends has in these relationships.

\section{Conflict of Interest}

The authors declare that they have no conflict of interest.

\section{References}

Adams, K., Sandy, L., Smith, L., \& Triglone, B. (2008). Drug use monitoring in Australia: 2007 annual report on drug use among police detainees. Research and public policy series no. 93. Canberra: Australian Institute of Criminology.

Angold, A., Costello, E. J., Messer, S. C., Pickles, A., Winder, F., \& Silver, D. (1995). The development of a short questionnaire for use in epidemiological studies of depression in children and adolescents. International Journal of Methods in Psychiatric Research, 5(237-249).

Australian Insititute of Health and Welfare (2011). 2010 National Drug Strategy Household Survey report. Drug Statistics Series no. 25.

Canberra: Australian Insititute of Health and Welfare.

Barnea, Z., Rahav, G., \& Teichman, M. (1987). The reliability and consistency of self-reports on substance use in a longitudinal study. British Journal of Addiction, 82(8), 891-898. 
Boden, J. M., Fergusson, D. M., \& Horwood, L. J. (2012). Alcohol misuse and violent behavior: Findings from a 30-year longitudinal study. Drug and Alcohol Dependence, 122, 135-141.

Dembo, R., Williams, L., Getreu, A., Genung, L., Schmeidler, J., Berry, E., et al. (1993). Longitudinal study of the relationship among marijuana/hashish use, cocaine use and delinquency in a cohort of high risk youths. Journal of Drug Issues, 21, 271-312.

Ellickson, P. L., Tucker, J. S., \& Klein, D. J. (2003). Ten-year prospective study of public health problems association with early drinking. Pediatrics, 111(949-955).

Ferguson, C. J., \& Meehan, D. C. (2011). With friends like these...: Peer delinquency influences across age cohorts on smoking, alcohol and illegal substance use. European Psychiatry, 26, 6-12.

Fergusson, D. M., \& Horwood, L. J. (2000). Alcohol abuse and crime: A fixed-effects regression analysis. Addiction, 95, 1525-1536.

Foshee, V. A., Karriker-Jaffe, K. J., Luz, M. R., H, Ennett, S. T., Suchindran, C., Bauman, K. E., et al. (2008). What accounts for demographic differences in trajectories of adolescent dating violence? An examination of intrapersonal and contextual mediators. Journal of Adolescent Health, 42(6), 596-604.

Glaser, R. R., Lee Van Horn, M., Arthur, M. W., Hawkins, J., \& Catalano, R. F. (2005). Measurement properties of the Communities That Care Youth Survey across demographic groups. Journal of Quantitative Criminology, 21, 73-102.

Green, K. M., Doherty, E. E., Zebrak, K. A., \& Ensminger, M. E. (2011). Association between adolescent drinking and adult violence: Evidence from a longitudinal study of urban African Americans. Journal of Studies on Alcohol and Drugs, 72(5), 701-710. 
Hawkins, J. D., Catalano, R. F., \& Miller, J. Y. (1992). Risk and protective factors for alcohol and other drug problems in adolescence and early adulthood: Implications for subtance abuse prevention. Psychological Bulletin, 112, 64-105.

Hawkins, J. D., Herrenkohl, T., Farrington, D. P., Brewer, D., Catalano, R. F., \& Harachi, T. W. (1998). A review of predictors of youth violence. In R. Loeber, \& D. P. Farrington (Eds.), Serious \& violent juvenile offenders: Risk factors and successful interventions (pp. 106-146). Thousand Oaks, CA, US: Sage Publications Inc.

Hu, L., \& Bentler, P. M. (1999). Cutoff criteria for fit indexes in covariance structure analysis: Conventional criteria versus new alternatives. Structural Equation Modeling: A Multidisciplinary Journal, 6(1), 1-55.

Huang, B., White, H. R., Kosterman, R., Catalano, R. F., \& Hawkins, J. D. (2001). Developmental associations between alcohol and interpersonal aggression during adolescence. Journal of Research in Crime and Delinquency, 38, 64-83.

Huckle, T., You, R. Q., \& Casswell, S. (2010). Socio-economic status predicts drinking patterns but not alcohol-related consequences independently. Addiction, 105(7), 1192-1202.

Hutchinson, S. R., \& Olmos, A. (1998). Behavior of descriptive fit indexes in confirmatory factor analysis using ordered categorical data. Structural Equation Modeling: A Multidisciplinary Journal, 5(344-364).

Jessor, R., \& Jessor, S. L. (1977). Problem Behavior and Psycho-social Development: A Longitudinal Study of Youth. New York, NY: Academic Press. 
Johnson, D. R., \& Creech, J. C. (1983). Ordinal measures in multiple indicator models: A simulation study of categorization error. American Sociological Review, 48, 398-407.

McMorris, B. J., Hemphill, S. A., Toumbourou, J. W., Catalano, R. F., \& Patton, G. C. (2007). Prevalence of substance use and delinquent behavior in adolescents from Victoria, Australia and Washington State, United States. Health Education and Behavior, 34, 634-650.

Moffitt, T. E. (1993). "Life-course-persistent" and "adolescent-limited" antisocial behavior: A developmental taxonomy. Psychological Review, $100,674-701$.

Morgan, A., \& McAtamney, A. (2009). Key issues in alcohol-related violence. Research in practice no. 4. Canberra: Australian Institute of Criminology.

Newcomb, M. D., \& McGee, L. (1989). Adolescent alcohol use and other delinquent behaviors: A one-year longitudinal analysis controlling for sensation seeking. Criminal Justice and Behavior, 16, 345-369.

Parks, K., Hsieh, Y.-P., Bradizza, C. M., \& Romosz, A. M. (2008). Factors influencing the temporal relationship between alcohol consumption and experiences with aggression among college women. Psychology of Addictive Behaviors, 22(2), 210-218.

Poynton, S., Donnelly, N., Weatherburn, D., Fulde, G., \& Scott, L. (2005). The role of alcohol in injuries presenting to St Vincent's Hospital Emergency Department and the associated short-term costs. Alcohol Studies Bulletin. Sydney: NSW Bureau of Crime Statistics and Research.

Schafer, J. L., \& Graham, J. W. (2002). Missing data: Our view of the state of the art. Psychological Methods, 7(2), 147-177. 
Sussman, S., Skara, S., Weiner, M. D., \& Dent, C. W. (2004). Prediction of violence perpetration among high-risk youth. American Journal of Health Behavior, 28(2), 134-144.

Swahn, M. H., \& Donovan, J. E. (2004). Correlates and predictors of violent behavior among adolescent drinkers. Journal of Adolescent Health, $34,480-492$.

Temple, J. R., Shorey, R. C., Fite, P., Stuart, G. L., \& Le, V. D. (2012). Substance use as a longitudinal predictor of the perpetration of teen dating violence. Journal of Youth and Adolescence, doi:10.1007/s10964-012-9877-1.

Thornberry, T. P., \& Krohn, M. D. (2000). The self-report method for measuing delinquency and crime. Measurement and Analysis of Crime and Justice, 4, 33-83.

Toumbourou, J. W., Stockwell, T., Neighbors, C., Marlatt, G. A., Sturge, J., \& Rehm, J. (2007). Interventions to reduce harm associated with adolescent substance use. Lancet, 369(9570), 1391-1401.

von Hippel, P. T. (2004). Biases in SPSS 12.0 missing value analyses. The American Statistician, 58(2), 160-164.

Wagner, E. F. (1996). Substance use and violent behavior in adolescence. Aggression and Violent Behavior, 1(4), 375-387.

Wei, E. H., Loeber, R., \& White, H. R. (2004). Teasing apart the developmental associations between alcohol and marijuana use and violence. Journal of Contemporary Criminal Justice, 20, 166-183.

White, H. R., Brick, J., \& Hansell, S. (1993). A longitudinal investigation of alcohol use and aggression in adolescence. Journal of Studies on Alcohol and Drugs, 11, 62-77. 
White, H. R., Fite, P., Pardini, D., Mun, E.-Y., \& Loeber, R. (2012). Moderators of the dynamic link between alcohol use and aggressive behavior among adolescent males. Journal of Abnormal Child Psychology, doi:10.1007/s10802-012-9673-0.

White, H. R., \& Hansell, S. (1996). The moderating effects of gender and hostility on the alcohol-aggression relationship. Journal of Research in Crime and Delinquency, 33, 450-470.

White, H. R., Loeber, R., Stouthamer-Loeber, M., \& Farrington, D. P. (1999). Developmental assocations between substance use and violence. Development and Psychopathology, 11, 785-803.

Windle, M. (1990). A longitudinal study of antisocial behaviors in early adolescence as predictors of late adolescent substance use: Gender and ethnic group differences. Journal of Abnormal Psychology, 99(1), 96-91.

Winters, K. C., Stinchfield, R. D., Henly, G., \& Schwartz, R. H. (1990). Validity of adolescent self-report of alcohol and other drug involvement. Substance Use and Misuse, 25(11), 1379-1395.

Xue, Y., Zimmerman, M. A., \& Cunningham, R. (2009). Relationship between alcohol use and violent behavior among urban african american youths from adolescence to emerging adulthood: A longitudinal study. American Journal of Public Health, 99(11), $2041-2047$.

Young, R., Sweeting, H., \& West, P. (2008). A longitudinal study of alcohol use and antisocial behavior in young people. Alcohol and Alcoholism, 43(2), 204-214. 


\begin{tabular}{|c|c|c|c|c|c|c|c|c|c|}
\hline & \multicolumn{3}{|c|}{ Grade 7} & \multicolumn{3}{|c|}{ Grade 9} & \multicolumn{3}{|c|}{ Grade 11} \\
\hline & Male & Female & alpha & Male & Female & alpha & Male & Female & alpha \\
\hline $\mathrm{n}$ & 387 & 450 & & 329 & 385 & & 314 & 402 & \\
\hline Age (years) & $12.97(0.38)$ & $12.94(0.40)$ & N/A & $15.18(0.38)$ & $15.13(0.39)$ & N/A & $17.04(0.41)$ & $16.97(0.41)$ & N/A \\
\hline Past year alcohol use frequency & $1.98(1.68)$ & $1.71(1.36)$ & N/A & $3.27(2.11)$ & $3.32(2.12)$ & N/A & $4.73(2.37)$ & $4.41(2.21)$ & N/A \\
\hline Heavy episodic drinking frequency & $1.14(0.51)$ & $1.09(0.44)$ & N/A & $1.55(0.98)$ & $1.54(0.96)$ & N/A & $2.09(1.20)$ & $1.84(1.08)$ & N/A \\
\hline Violent behavior frequency & $1.07(0.27)$ & $1.02(0.12)$ & 0.51 & $1.14(0.45)$ & $1.05(0.19)$ & 0.53 & $1.16(0.49)$ & $1.04(0.22)$ & 0.61 \\
\hline Family conflict & $1.93(0.75)$ & $1.99(0.76)$ & 0.82 & $2.11(0.70)$ & $2.29(0.78)$ & 0.83 & $2.20(0.73)$ & $2.28(0.79)$ & 0.84 \\
\hline Academic failure & $1.93(0.58)$ & $1.84(0.54)$ & 0.62 & $2.09(0.68)$ & $2.05(0.65)$ & 0.74 & $2.23(0.65)$ & $2.17(0.63)$ & 0.74 \\
\hline Interaction with antisocial peers & $0.15(0.29)$ & $0.10(0.26)$ & 0.70 & $0.39(0.57)$ & $0.25(0.43)$ & 0.83 & $0.52(0.73)$ & $0.28(0.47)$ & 0.87 \\
\hline Friends' use of drugs & $0.34(0.55)$ & $0.33(0.58)$ & 0.66 & $1.10(0.91)$ & $1.18(0.93)$ & 0.58 & $1.77(1.05)$ & $1.65(1.02)$ & 0.76 \\
\hline Depressive symptoms & $5.48(5.04)$ & $6.85(6.32)$ & 0.91 & $5.86(5.29)$ & $8.77(7.05)$ & 0.93 & $6.58(5.32)$ & $9.60(7.41)$ & 0.93 \\
\hline
\end{tabular}

Table 1. Means and standard deviations for each variable at each measurement point

Possible range for each variable: Past year alcohol use frequency (1-8), Heavy episodic drinking frequency (1-6), Violent behavior frequency (18), Family conflict (1-4), Academic failure (1-4), Interaction with antisocial peers (0-4), friends' use of drugs (0-4), Depressive symptoms (0-26)

Table 2. Rates of past year alcohol use, binge drinking and violence at each measurement point

\begin{tabular}{llll}
\hline Grade 7 & Grade 9 & Grade 11 \\
\hline
\end{tabular}




\begin{tabular}{|c|c|c|c|c|c|c|}
\hline & Male & Female & Male & Female & Male & Female \\
\hline & $\%$ & $\%$ & $\%$ & $\%$ & $\%$ & \\
\hline Past year alcohol use & 33.90 & 33.26 & 73.08 & 76.79 & 86.78 & 88.17 \\
\hline Heavy episodic drinking & 9.27 & 5.36 & 32.67 & 30.58 & 58.60 & 46.88 \\
\hline Violence & 9.98 & 2.68 & 12.47 & 5.36 & 12.47 & 3.79 \\
\hline
\end{tabular}

Note. Rates calculated as the number of participants who reported at least one occasion of the specified behavior, at the specified measurement point 


\begin{tabular}{|c|c|c|c|c|}
\hline & \multicolumn{2}{|c|}{ Past year alcohol use } & \multicolumn{2}{|c|}{ Heavy episodic drinking } \\
\hline & \multicolumn{4}{|c|}{ Grade 7} \\
\hline & $\mathrm{M}$ & $\mathrm{F}$ & $\mathrm{M}$ & $\mathrm{F}$ \\
\hline Past year alcohol use & 1 & 1 & & \\
\hline Heavy episodic drinking & $0.46 * *$ & $0.43 * *$ & 1 & 1 \\
\hline \multirow[t]{3}{*}{ Violence } & $0.17 * *$ & 0.09 & $0.19 * *$ & $0.14 * *$ \\
\hline & \multicolumn{4}{|c|}{ Grade 9} \\
\hline & $\mathrm{M}$ & $\mathrm{F}$ & $\mathrm{M}$ & $\mathrm{F}$ \\
\hline Past year alcohol use & 1 & 1 & & \\
\hline Heavy episodic drinking & $0.58 * *$ & $0.64 * *$ & 1 & 1 \\
\hline \multirow[t]{3}{*}{ Violence } & $0.17 * *$ & $0.26 * *$ & $0.19 * *$ & $0.17 * *$ \\
\hline & \multicolumn{4}{|c|}{ Grade 11} \\
\hline & $\mathrm{M}$ & $\mathrm{F}$ & $\mathrm{M}$ & $\mathrm{F}$ \\
\hline Past year alcohol use & 1 & 1 & & \\
\hline Heavy episodic drinking & $0.61 * *$ & $0.62 * *$ & 1 & 1 \\
\hline Violence & $0.19 * *$ & 0.08 & $0.18 * *$ & $0.09 *$ \\
\hline
\end{tabular}

Table 3. Cross sectional correlations between variables at each measurement point ${ }^{*} \mathrm{p}<0.05,{ }^{*} p p<0.001$ 


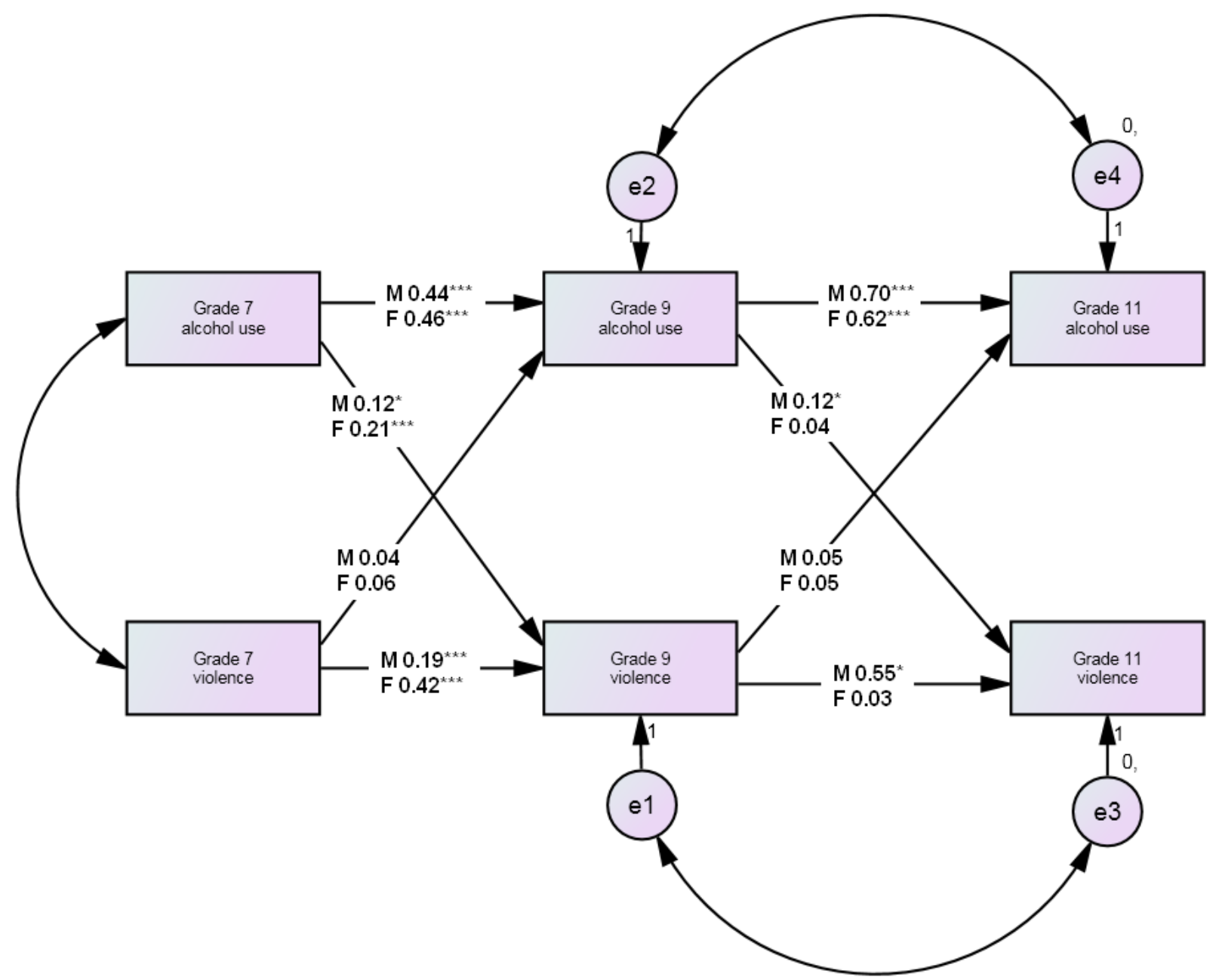

Fig. 1 Cross-lagged path model of the relationship between alcohol use and violence. $M=$ Males, $F=$ Females. Standardized coefficients are presented. $* \mathrm{p}<0.05, * * \mathrm{p}<0.01, * * * \mathrm{p}<0.001$ 


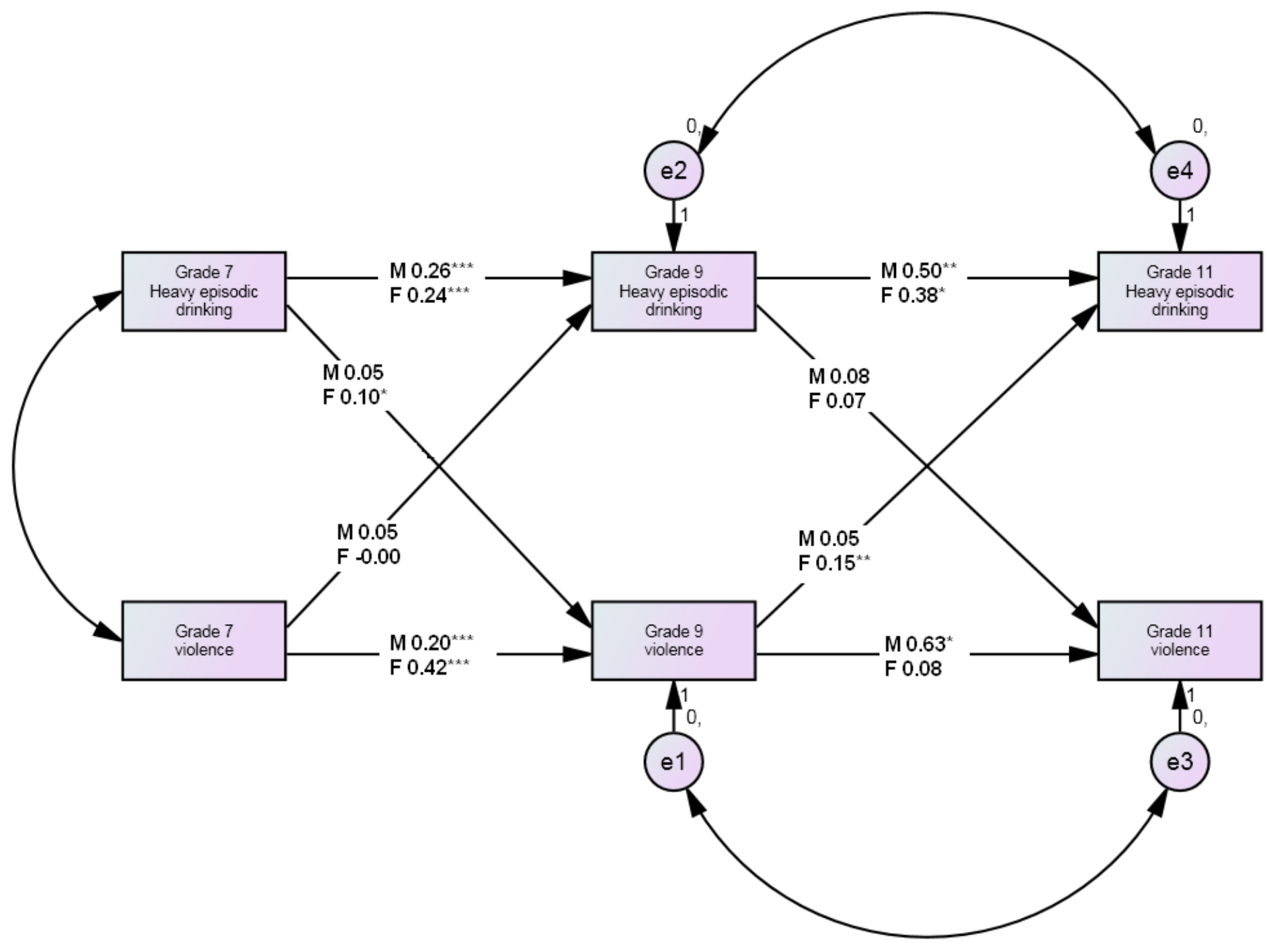


Fig. 2 Cross-lagged path model of the relationship between heavy episodic drinking and violence. $\mathrm{M}=$ Males, $\mathrm{F}=$ Females. Standardized coefficients are presented. $* \mathrm{p}<0.05,{ }^{* *} \mathrm{p}<$ $0.01, * * * \mathrm{p}<0.001$ 